\title{
LA DOBLE DIMENSIÓN DE LO PENITENCIARIO Y LA NECESIDAD DE UNA POLÍTICA PÚBLICA CARCELARIA DE COMUNICACIÓN EN COLOMBIA 1
}

\author{
Pedro Elías Castañeda Quitián \\ Universidad Pedagógica y Tecnológica de Colombia (UPTC)
}

\begin{abstract}
https://doi.org/10.33676/EMUI_nomads.55.05
Resumen: En este texto se haba sobre la importancia de la comunicación intersubjetiva como forma de mantener ciertos vínculos identitarios y como expresión de derechos de las personas privadas de la libertad. Se aborda dicha temática de manera reflexiva y teórica y a la luz de la Sentencia de la Corte Constitucional colombiana T-276 DE 2017, la cual considera el derecho a la comunicación como un derecho fundamental de las personas privadas de la libertad que debe ser respetado y posibilitado mediante una política pública. Se hace énfasis en el caso de las videoconferencias, como una alternativa a los medios institucionales convencionales, para poder concluir finalmente que estas constituyen una opción de empoderamiento para superar lo que el sociólogo Loïc Wacquant conoce como gueto judicial. Finalmente se presenta la idea de que ello puede llegar a conformar una propuesta pedagógica de empoderamiento y resocialización para personas privadas de la libertad.
\end{abstract}

Palabras clave: comunicación intersubjetiva, empoderamiento, gueto judicial, presente eterno, doxa punitiva neoliberal.

\section{The Double Dimension of the Penitentiary and the Need for a Prison Public Policy of Communication in Colombia}

\begin{abstract}
In this text there was talk about the importance of intersubjective communication as a way of maintaining certain identity bonds and as an expression of the rights of persons deprived of liberty. This subject is approached in a reflective and theoretical manner and in light of the Judgment of the Colombian Constitutional Court T-276 OF 2017, which considers the right to communication as a fundamental right of persons deprived of liberty that must be respected and respected. made possible through a public policy. Emphasis is placed on the case of videoconferences, as an alternative to conventional institutional means and an empowerment option to overcome what the sociologist Loïc Wacquant knows as a judicial ghetto. Finally, the idea is presented that this can lead to a pedagogical proposal of empowerment and resocialization for people deprived of their freedom.
\end{abstract}

Key Words: Intersubjective communication, empowerment, judicial ghetto, eternal present, punitive neoliberal doxa.

\footnotetext{
1 Este texto ha sido elaborado dentro del marco de investigación del semillero Sapere Aude adscrito al grupo Primo Levi de la Universidad Pedagógica y Tecnológica de Colombia (UPTC), y como requisito de grado dentro de mis estudios de maestría en Derechos Humanos de dicha institución.
} 


\section{Introducción}

En cuanto a lo que atañe al derecho a ta comunicación en el sistema carcelario colombiano, en la sentencia T-276 del año 2017, la Corte Constitucional de Colombia advirtió que el derecho a la comunicación de la persona privada de la libertad (PPL) con el mundo exterior y con sus familiares, se halla ligado a la protección constitucional de la integridad de la familia, de la intimidad familiar y de la inviolabilidad de las comunicaciones. Dicha sentencia, cabe decir, responde a una acción de tutela que fue interpuesta por Óliver Fernández contra Prepacol SAS a razón de que los teléfonos celulares no se encontraban en correcta operación en la cárcel de Guaduas, así como a otra acción elevada por Luis Lezama Campo contra la Cárcel de Cómbita, en el departamento de Boyacá, a razón de que las cartas enviadas a sus familiares en noviembre de 2014 y en septiembre de 2015, nunca llegaron a sus destinatarios. De esa forma, la Corte Constitucional colombiana se sirve acertadamente de dichos casos para hablar de la comunicación como derecho fundamental de la persona privada de la libertad, y partiendo de allí, en el presente artículo se procede a relacionar dicha sentencia con el derecho emergente a la comunicación familiar de personas privadas de la libertad a través del sistema de viodeconferencia.

Hablar sobre el sistema de videoconferencias como derecho emergente de la persona privada de la libertad, lleva a que, por lo menos a los fines de este texto, el énfasis se coloque en la importancia de la comunicación intersubjetiva del ser humano como forma de resocialización. En torno a lo que respecta a la comunicación intersubjetiva, bien podemos entenderla, al menos en parte, como aquella necesidad de configurar formas de identificación con una serie de elementos socioculturales que no solo determinan la individualidad y la capacidad de agencia de las personas (Fernández y Rizo, 2009), sino asimismo derechos tales como la libertad de expresión o de libre desarrollo de la personalidad entre otros. Una individualidad y unos derechos los cuales pueden verse ampliamente restringidos por la pobreza, la exclusión y la precariedad y más aún en un país con un gran nivel de desigualdad como Colombia.

En otras palabras, a pesar del reconocimiento del derecho a la comunicación en la sentencia T-276 de 2017, dicho derecho en el plano fáctico se ve restringido por la delimitación o poco goce de otros derechos que actúan de manera integral con el primero. De ahí la 
importancia de abordar este trabajo desde una perspectiva crítica de derechos humanos en la cual pueda integrarse una mirada institucional, constitucionalista y de prácticas sociales y de derechos en las cárceles de Colombia. Ello teniendo en cuenta que la mencionada Sentencia T276 de 2017, menciona que es necesario avanzar en una política pública por la cual se agilice y se haga más efectivo el derecho a la comunicación de personas privadas de la libertad. Pues bien, para la construcción de una política tal, hay que considerar una gran gama de factores a favor como el reconocimiento de la comunicación como derecho fundamental en la sentencia mencionada, o factores en contra como la corrupción en las cárceles o los citados problemas de exclusión y pobreza que amenazan derechos que en el plano real se desenvuelyen de manera integral.

Partiendo de lo anterior, el objetico de este texto se centra en relacionar desde un punto de vista crítico y de derechos humanos, el derecho emergente de la videoconferencia con la propuesta de la Sentencia T276 de 2017 de configurar una política pública que facilite el derecho a la comunicación de personas privadas de la libertad. La metodología a tener en cuenta se basa en la reflexión teórica y doctrinal a partir de material jurídico y académico. Todo ello partiendo de la idea que se expondrá más adelante, de que una política pública carcelaria sobre comunicación, debería tener un enfoque pedagógico o de facilitación de ciertas herramientas básicas por las cuales se pueda colocar el énfasis en la resocialización de la persona. Es decir, una política pública que sea afín al tratamiento penitenciario tal y como se encuentra reglamentado en Colombia por la Resolución 7302 del 23 de noviembre de 2005 del INPEC. Es decir, como:

...el conjunto de mecanismos de construcción grupal e individual, tendientes a influir en la condición de las personas, mediante el aprovechamiento del tiempo de condena como oportunidades, para que puedan construir y llevar a cabo su propio proyecto de vida, de manera tal que logren competencias para integrarse a la comunidad como seres creativos, productivos, autogestionarios, una vez recuperen su libertad.

\section{Políticas públicas carcelarias y su sentido pedagógico}

Hablar de resocialización, como parte de una política pública y de un tratamiento penitenciario que debe ser observante de la dignidad humana y de las necesidades particulares de la personalidad de cada sujeto, y que sea además "progresivo y programado e individualizado hasta donde sea posible" tal y como señala Artículo 143 de la Ley 65 de 1993, nos lleva a hablar de educación y pedagogía. En términos generales, lleva a que se hable de la facilitación de ciertas herramientas 
a las personas privadas de la libertad como opción de vida. En Colombia, a través de la Subdirección de Tratamiento y Desarrollo del INPEC (Instituto Nacional Penitenciario y Carcelario creado mediante el Decreto 2160 de 1992), se lleva a cabo el diseño y ejecución de programas penitenciarios (Cuesta Quimabaya, 2015). En dicho contexto se encuentra el Plan de Acción y Sistema de Oportunidades (PASO), definido en la Resolución 2392/2006, como:

El conjunto de programas educativos, laborales y de enseñanza estructurados con un componente psicosocial, cultural, recreativo, deportivo, axiológico y espiritual que ofrece el Sistema Penitenciario y Carcelario a los internos (as), como espacio de reflexión y crecimiento personal orientado hacia la integración social positiva, prevaleciendo el respeto a la dignidad humana, a las garantías constitucionales y a los derechos humanos universalmente reconocidos (Resolución 2392/2006).

Como se puede apreciar el sistema penitenciario colombiano busca, en principio, optimizar las opciones de vida de las personas privadas de la libertad. Sin embargo, cabe preguntarse si en realidad la misma configuración actual de lo carcelario permite la resocialización y hașta qué punto las cárceles no son más que formas de desechar lo indeseable, entre comillas, de la sociedad, mientras que el discurso de la resocialización no es más que la mera cara ética que sirve para enmascarar un sinnúmero de prácticas sociales de dominio y control social. En otras palabras, preguntarnos por la realidad misma de lo penitenciario en la actualidad, tal y como se hará en aparatados posteriores, ayudará a comprender o siquiera a analizar teóricamente si la resocialización es posible y qué tipo de bien representa para la sociedad en su conjunto.

En cuanto a lo que atañe a la política pública, a grandes rasgos esta puede ser entendida como la solución a una situación definida como problemática, basada a su vez en la "configuración de una necesidad social y cultural, de visibilidad y resolución de requerimientos sociales y culturales" (Lozano Ayala 2008, pág. 17). La problemática en este caso sería la deficiencia en el derecho a la comunicación de personas privadas de la libertad en el sistema penitenciario colombiano, lo cual queda reflejado en la Sentencia T-276 de 2017. La otra cara de la moneda es la posibilidad de la educación y la resocialización en una política pública tal. De hecho, se podría decir que a razón de los mismos parámetros del tratamiento penitenciario, es consecuencia necesaria y directa que las políticas públicas en materia de derechos, potencien la facilitación de opciones de vida y de herramientas múltiples para la resocialización de los reclusos. Sin embargo volvemos a la pregunta que será estudiada más adelante, sobre si las mismas realidades penitenciarias en sus aspectos sociales, culturales y económicos, lo permite. 
Por otra parte, cabe tener en cuenta que la educación en el sistema penitenciario contemporáneo es asumida hoy día como un desafío necesario que es respaldado por una gran cantidad de normas y marcos socio-jurídicos como por ejemplo el artículo 26 de la Declaración Universal de los Derechos Humanos en el cual consta que toda persona tiene derecho a la educación (Del Pozo, 2017). La educación, por tanto, es así entendida ya que supone la posibilidad de una reducción de los factores de riesgo que condujeron a la acción delictiva, $y$, por otra parte, permite cierta mejora en la in/reinserción social y laboral de las personas penadas.

De esa forma, y de acuerdo con Francisco José del Pozo Serrano (2017), "Ios procesos formativos socioeducativos, pueden actuar por tanto, como un factor de protección que prevenga, reduzca o actúe en la deshabituación de la drogodependencia, y por supuesto, potenciar los procesos de transformación en el desarrollo vital" (p. 345). Sin embargo, de acuerdo con el teórico Loïc Wacquant (2010a, 2010b), existen correlatos de pobreza y exclusión en la misma forma en la cual opera lo punitivo hoy día. Partiendo de allí, dichos correlatos vendrían a limitar en alto grado la posibilidad de una educación y de un empoderamiento cien por ciento efectivos. No obstante, también puede ser cierto que contemplar nuevas formas de pedagogía y empoderamiento, vendrían a hacer más probables y manejables aquellos fines que se persigue con la educación hacia las personas privadas de la libertad. Y por fortuna, nuevas formas de empoderar pueden surgir fácilmente hoy día a través de las tecnologías de la información. De esa forma, para el caso concreto que nos interesa, se habla desde un punto de vista teórico y desde una perspectiva crítica, de las videoconferencias como posibilidad de comunicación intersubjetiva y como forma de reivindicación en derechos.

Sin embargo, también hay que tener en cuenta que, de acuerdo con Deiby Alberto Sáenz-Rodríguez (2015), en los procesos de reinserción social de la actual política pública colombiana, se encuentran una serie de fallas o falencias representadas por décadas en la reinserción social de los penados y que hunden su razón de ser en cuestiones tales como la inestabilidad de las políticas estatales y la indiferencia ante los problemas carcelarios. De hecho, de acuerdo con Sáenz-Rodríguez (2015), la falta de integralidad y de asociar la resocialización al conjunto amplio de la sociedad también ha sido un problema. En palabras del autor:

El compromiso institucional para resolver los problemas de la Resocialización por medio del Tratamiento Penitenciario ha sido limitado al interno, al individuo, como si se tratara de restablecer la pieza perdida, olvidándose de que este interno es el producto de un sistema socio-económico, familiar, cultural y político al cual debe volver y el cual de una u otra manera lo llevó allá. 
Un de las principales características del tratamiento penitenciario como es concebido hoy día en Colombia, es la idea de un sistema progresivo (Ley 65 de 1993, art. 12), mediante el cual la pena disminuye en función del estudio de la conducta y comportamiento de la persona privada de la libertad. El sistema PASO atrás mencionado, por ejemplo, se divide en tres fases secuenciales asociadas con unos propósitos particulares para el recluso. De esa forma, encontramos el PASO inicial para el fortalecimiento de capacidades, el PASO medio para la preparación para la productividad y el PASO final para interiorizar la reinserción (Cuesta Quimabaya, 2015). De esa forma, la educación no solo sería un elemento esencial de una política pública carcelaria basada en un tratamiento penitenciario que facilite opciones de vida, sino un elemento esencial de un sistema que debe ser progresivo para el individuo y que no por ello debe estar aislado de la sociedad en su conjunto. Para finalizar este apartado, bien cabe por ahora contemplar la opción de las videoconferencias como un programa que haga parte del sistema PASO.

\section{Marco jurídico del derecho a la comunicación en las cárceles del mundo y en Colombia}

Antes de entrar en materia en cuanto a lo que atañe a relacionar los aspectos positivos de la construcción de una política carcelaria de comunicación como ciertas disposiciones jurídicas, y los aspectos negativos como la exclusión, la pobreza y la precariedad en Colombia, con el sistema penitenciario en sí mismo y el derecho a la comunicación en cuanto tal, cabe, en primer lugar, hacer un breve recuento de los instrumentos jurídicos con que cuentan las personas privadas de la libertad en los distintos sistemas como el Sistema Internacional de los Derechos Humanos o el Sistema Interamericano:

1. Instrumentos jurídicos generales:

a) Declaración Universal de los Derechos Humanos:

b) Pacto Internacional de Derechos Civiles y Políticos

c) Convención Americana Sobre Derechos Humanos

2. Instrumentos específicos:

a) Reglas mínimas para el tratamiento de los reclusos o reglas Nelson Mandela.

b) Principios básicos para el tratamiento de los reclusos. 
c) Conjunto de principios para la protección de todas las personas sometidas a cualquier forma de detención o prisión.

d) Código de conducta para funcionarios encargados de hacer cumplir la ley

e) Convención contra la tortura y otros tratos o penas crueles, inhumanos 0 degradantes (apartes pertinentes: definiciones y obligaciones).

f) Protocolo facultativo de la Convención contra la tortura y otros tratos o penas crueles, inhumanos o degradantes.

g) Convención interamericana para prevenir y sancionar la tortura (partes pertinentes: definiciones y obligaciones).

3. Instrumentos nacionales:

a) Constitución política de Colombia de 1991.

b) Sentencia T-388 de 2014 .

c) Sentencia T-76 de 2015

En cuanto a lo que atañe a las Reglas Mínimas de las Naciones Unidas para el Tratamiento de los Reclusos, también conocidas como Reglas Nelson Mandela, es necesario considerar que el 17 de diciembre de 2015 la Asamblea General de las Naciones Unidas, las aprobó tras un arduo proceso de deliberación y negociación en el cual participaron activamente autoridades públicas, expertos y organizaciones de derechos humanos. Se le denomina "Reglas Nelson Mandela", en homenaje al expresidente sudafricano, Nelson Rolihlahla Mandela, quien permaneció 27 años encarcelado como parte de su lucha por los derechos humanos.

Sobre el derecho a la comunicación, en la Regla 58, que es la que trata la elación con el exterior, podemos encontrar: 1. Los reclusos estarán autorizados a comunicarse periódicamente, bajo la debida vigilancia, con sus familiares y amigos: a) Por correspondencia escrita y por los medios de telecomunicaciones, electrónicos, digitales o de otra índole que haya disponibles; y b) Recibiendo visitas.

Por su parte, y en cuanto a derechos generales en otros instrumentos nacionales, en el Código penitenciario y carcelario, modificado por la Ley 1709 de 2014, se precisa que:

Artículo 10. Adicionado por la Ley 1709 de 2014, artículo 60. Intervención mínima. El sistema penitenciario velará por el cumplimiento delos derechos y las garantías de los internos; los que solo podrán ser limitados según lo dispuesto en la Constitución, los tratados internacionales, las 
leyes y los reglamentos del régimen interno del Establecimiento Penitenciario y Carcelario.

Artículo 5, Ley 65 de 1993. Modificado por la Ley 1709 de 2014, artículo $4^{\circ}$. Respeto a la dignidad humana. En los establecimientos de reclusión prevalecerá el respeto a la dignidad humana, a las garantías constitucionales y a los Derechos Humanos universalmente reconocidos. Se prohíbe toda forma de violencia síquica, física o moral. Las restricciones impuestas a las personas privadas de la libertad estarán limitadas a un estricto criterio de necesidad y deben ser proporcionales a los objetivos legítimos para los que se han impuesto.

Como se puede apreciar, gran parte de los instrumentos jurídicos seleccionados no solo tratan el derecho a la comunicación de las personas privadas de la libertad sino que hablan de derechos en su sentido amplio y de la visión de la pena como un hecho social predispuesto a la resocialización. De esa forma, por ejemplo, en la Sentencia T-718 del 28 de septiembre de 1999 se considera que la pena no tiene un sentido de retaliación social o de venganza sino un carácter resocializador (Sentencia T-718 del 28 de septiembre de 1999).

\section{Derechos humanos y resocialización como parte de lo punitivo en el mundo actual}

De acuerdo con el teórico Massimo Pavarini (2011), la fundamentación filosófica inicial de lo penitenciario lleva a contemplar la pena de privación de la libertad por medio de una ejecución carcelaria, dentro de la esfera del "no-derecho". Ello a la par que la cárcel es instituida en lo vivencial, como una forma de producción de sufrimiento como privación y una limitación de derechos y expectativas (Marí, 1993). Sin embargo, Pavarini (2009), también nos dice que con los cambios que ha traído el paso del tiempo y la llegada de una modernidad avanzada, el gobierno administrativo del control penal tiende hoy día a construirse alrededor de objetivos sistémicos que divergen radicalmente del uso simbólico de la penalidad. Objetivos tales como la resocialización por medio de la educación. De esa forma, por medio de un objetivo tal, lo carcelario regresa en parte a la esfera del derecho. Y así debería ser, ya que las personas privadas de la libertad siguen siendo seres humanos titulares de varios derechos humanos. Y visto así, toda propuesta pedagógica para personas privadas de la libertad, vendría configurar un avance significativo en materia de derechos.

Partiendo de allí, resulta altamente relevante el tema de la comunicación intersubjetiva en relación a las personas privadas de la libertad. Recuérdese que la comunicación intersubjetiva puede ser entendida en parte como aquella necesidad de configurar formas de 
identificación con una serie de elementos socioculturales que no solo determinan la individualidad y la capacidad de agencia de las personas (Fernández y Rizo, 2009), sino asimismo derechos tales como la libertad de expresión o de libre desarrollo de la personalidad entre otros. De modo que propuestas pedagógicas que afiancen dicha forma de comunicación, redundará en avances en derechos y en la misma resocialización del recluso. Sin embargo, a pesar del reconocimiento de lo penal dentro de la esfera del derecho y de los derechos humanos a partir de objetivos sistémicos, de cualquier forma se sigue entiendo que "Ia prisión debe ser un microcosmo de una sociedad perfecta donde los individuos se hallan aislados en su existencia moral, pero donde su reunión se efectúa en un encuadramiento jerárquico estricto, sin relación lateral no pudiendo hacerse la comunicación más que en el sentido de la vertical" (Foucault 1975, pág. 218). En otras palabras se sigue entiendo que los establecimientos penitenciarios son lugares de control y vigilancia, y en dicho contexto un tema como el de la regulación de la comunicación intersubjetiva no deja de ser un tema sumamente complejo.

Con el fin de delimitar un poco el amplio campo de la comunicación intersubjetiva, bien podríamos enfocarnos en la efectividad del derecho a la comunicación familiar de las personas privadas de la libertad a través, como ya se había mencionado anteriormente, del servicio institucional de videoconferencia. La videoconferencia, cabe agregar, es un sistema de comunicación que permite mantener entrevistas remotas con personas privadas de la libertad, en forma síncrona, y, prácticamente, en tiempo real. Esta comunicación se puede hacer punto a punto, entre dos interlocutores, o multipunto, donde pueden estar conectadas simultáneamente personas de distintos lugares del mundo. Ello, en principio, facilitaría la interacción social como elemento de resocialización y como forma de garantizar, al menos en parte, el ejercicio de derechos del que deben de gozar muchas personas privadas de la libertad.

Pues bien, en el Instituto Nacional Penitenciario y Carcelario INPEC, en Colombia, el sistema de videoconferencias en principio es utilizado para asuntos judiciales, pero así mismo viene siendo utilizado de manera restringida para "visitas virtuales" o comunicación de personas privadas de la libertad con su núcleo familiar, según el procedimiento que tiene la entidad para tal efecto. Razón por la cual bien podríamos entenderlo como un derecho emergente que no solo facilita la consideración de lo penitenciario como resocialización, sino como una forma de superar, al menos en parte, los correlatos de marginalidad, pobreza y exclusión que tienen lugar dentro de dicho ámbito, en otras palabras, lo que Wacquant (2010a, 2010b), conoce como la doxa punitiva neoliberal de la cual se hablará más adelante. Pero, ¿en qué medida la resocialización en verdad los supera? No olvidemos que estamos haciendo mención a unos correlatos de pobreza y exclusión que no 
dejan de tener presencia y de afectar a los reclusos, por más que existan propósitos sistémicos. Como se verá más adelante en este texto, existe una doble dimensión de lo penitenciario, unos aspectos negativos y otros positivos basados en la idea de resocialización, y la forma en la que esta última pueda imponerse depende en alto grado de la efectividad de las políticas públicas carcelarias.

No olvidemos que la política carcelaria, asociada a la función del sistema penal e incluso del sistema social, se ha definido en perspectiva del goce efectivo de los derechos cuando se afirma el objetivo resocializador de la pena privativa de la libertad. Por ello, el tratamiento penitenciario, según el artículo 10 de la Ley 65 de 1993:

Tiene como finalidad alcanzar la resocialización del infractor de la ley penal mediante el examen de su personalidad y a través de la disciplina, el trabajo, el estudio, la formación espiritual, la cultura, el deporte y la recreación, bajo un espíritu humano y solidario.

Su objetivo, por otra parte y según el artículo 142 del Código Penitenciario es "preparar al condenado mediante su resocialización para la vida en libertad. Es decir, el propósito sistémico de la resocialización, involucra un punto de vista y de acción que rebasa no solo la antigua concepción de penalidad mencionada al inicio de este apartado sino el mismo hecho de vigilar y controlar.

\section{El derecho a la comunicación y el sistema carcelario colombiano}

La problemática del sistema penitenciario y carcelario es un asunto que se encuentra ampliamente diagnosticado en recientes pronunciamientos de la Corte Constitucional Colombiana (Sentencia T388 de 2014 y T-762 de 2015), que ponen de relieve el "estado de cosas inconstitucional" frente a la responsabilidad del Estado con las personas privadas de la libertad en lo que respecta a garantía y goce efectivo de derechos. Y aunque dichas sentencias analizan el núcleo central de derechos tales como la salud, la dignidad y la integridad personal, nada se dice en ellos acerca de la importancia del derecho a la comunicación y el impacto que tienen las relaciones sociales y afectivas sobre las personas privadas de la libertad en el proceso de reinserción social. Ello es así ya que interesa más hacer frente al hacinamiento producto, de acuerdo a la corte constitucional, de una exacerbada política criminal lque bien encuadraría en las características de la doxa punitiva neoliberal de Wacquant que veremos más adelante), que en encarar la resocialización en sí misma y por tanto temas como la educación. Es así como una de las principales medidas en la Sentencia T-762 de 2015 para mejorar las condiciones carcelarias y superar el estado de cosas inconstitucional, es, por ejemplo: 
127. El objetivo es que cada una de las personas detenidas en Colombia cuente con una superficie de $20 \mathrm{~m}^{2}$ (o más en el caso de las personas en situación de discapacidad física, si fuere del caso) en el interior de la cárcel en la que se le haya recluido, entendiendo por tal aquella que resulta de sustraer del área total del suelo del penal, aquella a la que los presos no tienen ningún acceso.

La comunicación intersubjetiva, sin embargo, es bastante importante en este contexto ya que un gran porcentaje de personas privadas de la libertad se encuentran lejos de sus núcleos familiares, debido a que en ocasiones los traslados de estas personas por parte del INPEC a diversos establecimientos de reclusión, obedece a motivaciones por "administrar" los cupos carcelarios o por motivos de seguridad, lo cual afecta de manera trascendental ese vínculo con los seres queridos. Y si bien es cierto que en principio el derecho a la comunicación familiar está garantizado, para analizar el verdadero aspecto fáctico de la comunicación intersubjetiva como garantía de derechos, es necesario cuestionar cuáles son sus limitaciones reales en la práctica y bajo qué procesos y gramáticas de poder y exclusión, propias de una doxa punitiva neoliberal tiene lugar.

De ahí la hipótesis de que la comunicación como derecho de las personas privadas de la libertad, y entre ella la comunicación intersubjetiva que permiten los actuales medios de la información, y para el caso en concreto que nos interesa, las videoconferencias, se ve ampliamente limitada por los correlatos de marginalidad, exclusión y pobreza con que opera la ya mencionada doxa punitiva neoliberal. Sin embargo, la comunicación intersubjetiva es necesaria no solo como expresión de derechos sino para asegurar la misma resocialización, ya que representa un gran impulsor. Recordemos que la intersubjetividad requiere de una interacción social que tiene su origen en las construcciones referentes al otro (Fernández y Rizo, 2009). Se trata, de hecho, de una relación donde cada sujeto es al mismo tiempo un elemento del ambiente de la otra persona (Fernández y Rizo, 2009). Una relación donde tienen lugar un conjunto de experiencias comunes al mundo externo $y$, por tanto, una forma de establecer $y$ mantener vínculos identitarios $y$, en esa medida, de otorgarle significaciones al recluso.

En cuanto a lo que respecta al Código Penitenciario y Carcelario colombiano, en el artículo 110 (y siguientes), se consagra el derecho de las personas privadas de libertad a sostener comunicación con el exterior y de recibir noticias periódicas respecto de la vida nacional o internacional. En el caso que se trate de un detenido, al ingresar al centro de reclusión tiene derecho de comunicar su aprehensión tanto a su familia como a su abogado. El director del lugar de reclusión establecerá en el reglamento interno el horario y las modalidades de comunicación, entre las que se encuentran: (i) enviar y recibir correspondencia, para lo cual los internos gozan de franquicia postal; (ii) 
recibir visitas familiares, profesionales, de autoridades judiciales y administrativas, y de los medios de comunicación; (iii) contar con un sistema de información que contenga los hechos más importantes de la vida nacional e internacional; y (iv) en caso excepcional y en igualdad de condiciones, tener la posibilidad de hacer llamadas telefónicas, debidamente vigiladas. La Corte Constitucional ha sostenido que el derecho de los detenidos intramuros a la comunicación tiene como soporte el reconocimiento que hace el ordenamiento jurídico a los directores de los establecimientos de reclusión para instaurar restricciones a su ejercicio, las cuales deben corresponder al cumplimiento de tos objetivos de la actividad carcelaria. (T-266 de 2013).

Del contenido de las normas del Código Penitenciario y Carcelario, se logra establecer, que si bien no se hace una distinción puntal entre las visitas familiares y las visitas conyugales o íntimas, sí se puede concluir que las visitas de familiares y amigos reciben un tratamiento diferente $\mathrm{e}$ independiente de las íntimas, estableciendo incluso en el artículo 112A que debe haber dos momentos distintos cuando visitan a una persona privada de la libertad sus familiares menores de edad y cuando se lleva a cabo la visita íntima. Igualmente, de los dos artículos referenciados, se puede concluir la importancia que la Ley 65 de 1993 le da al derecho a la familia, materializada en la posibilidad de visitas que puede recibir con cierta periodicidad una persona que cumple una pena en un Centro Penitenciario y Carcelario.

La garantía de la visita familiar constituye en sí misma un derecho de los reclusos en conexidad con el derecho fundamental a la familia y a la intimidad. Adicionalmente, puede verse como un mecanismo de resocialización que debe ser procurado por el Estado como parte del desarrollo de los principios que infunden su política criminal y su sistema penal. La garantía del derecho a la visita familiar es una herramienta para el fortalecimiento de su vínculo que tiene efectos no solo en la resocialización, sino también en la disciplina dentro de los centros penitenciarios. (T-378 de 2015).

Uno de los avances que podemos mencionar en esta materia que estamos tratando, consiste en que el Ministerio de Tecnologías de la Información y las Comunicaciones y los ministerios de Trabajo y de Justicia, en junio de 2015 firmaron un convenio para diseñar e implementar un plan maestro de Teletrabajo para el sector Justicia que permita construir un modelo enfocado hacia la inclusión sociolaboral de población privada de la libertad y la innovación organizacional del sector a través del trabajo remoto. No obstante, uno de los hitos más representativos, desde el punto de vista judicial, es la Sentencia T-256 de 2017, cuya idea de fondo es que:

El problema de los servicios e implementos para la comunicación de los reclusos con el mundo exterior, está ligado necesariamente a las causas 
que dieron fundamento al $\mathrm{ECl}$, esto es, a la falta de una política pública en la materia que se fundamente en el respeto de la dignidad humana de la población carcelaria, se concentre en el papel rehabilitador de la sanción penal, y responda de forma preventiva y no como una reacción ante los problemas coyunturales. Es la inadecuada planificación, construcción y funcionamiento de los establecimientos penitenciarios y carcelarios, lo que convierte en insuficientes los medios y recursos destinados a satisfacer las garantías de sus derechos, y a su vez, el hacinamiento y la falta de garantías de sus derechos, responden a una política pública en materia criminal y penitenciaria desarticulada con la función constitucional de la sanción penal (Sentencia T-256 DE 2017, numeral 4.5).

En torno a lo que atañe a una política pública de comunicación, la parte final de resoluciones, la Sentencia T-256 de 2017, señala en su resolución décima:

Décimo. - Solicitar Al Gobierno Nacional a través del Ministerio para las Tecnologías de la Información y las Comunicaciones que en el transcurso de un año, en coordinación con el INPEC, tome las medidas adecuadas y necesarias para implementar un modelo piloto de acceso a internet $u$ otros medios de comunicación que contribuyan a hacer más eficiente la comunicación de las personas privadas de la libertad con sus familiares, así como su acceso a la información sobre el mundo exterior, a los programas de educación virtual y al conocimiento sobre el manejo de las nuevas tecnologías.

De esa forma, el sistema de videoconferencias bien podría estar ligado a una futura política pública carcelaria en materia de comunicaciones, razón por la cual se debe evitar que dicha política sea reducida a una política meramente de comunicación celular y a su vez, se podría siquiera bosquejar la posibilidad de que el sistema de videoconferencias se asocie al sistema PASO y que se considere que la capacitación en herramientas computacionales y ofimáticas es parte efectiva de la resocialización.

\section{El gueto judicial y la doble dimensión de lo punitivo en la actualidad}

De acuerdo con el sociólogo francés Loïc Wacquant (2010a, 2010b), las cárceles actúan como un contenedor y como un gueto jurídico en el cual se arrojan a las personas indeseables o problemáticas para la sociedad de mercado. Nos dice el autor mencionado, asimismo, que los gobiernos actuales se rinden a la tentación de apoyarse en la policía, los tribunales y la prisión para refrenar los desórdenes generados por el desempleo masivo, la generalización del trabajo asalariado precario y el hundimiento de la protección social, al mismo tiempo que entre los paradigmas punitivos tiene lugar hoy por hoy, una corriente 
internacional globalizadora con Estados Unidos a la cabeza de hipercarcelización. En otras palabras el neoliberalismo empuja a combatir no la pobreza sino a los pobres o aquellos que se ven inmersos dentro de una $u$ otra gramática de exclusión como bien lo puede ser la raza o cualquier otra categoría de exclusión. Al ultraliberalismo económico, de hecho, le corresponde así la ultra-represión de las incivilidades mediante la máxima de "tolerancia cero" (Lutz, 2013).

Por otra parte, se involucra a la ciudadanía trabajadora que se mueve dentro del sistema neoliberal para crear una red ciudadana punitiva, y en general toda una mentalidad ciudadana de la represión, por la cual se ofrecen recompensas y se garantiza el anonimato de los denunciantes de las infracciones, siendo el problema que dicha mentalidad se mueve a su vez dentro de categorías de exclusión y poder, y de esa forma se combate socialmente a personas desfavorecidas o indeseables (Lutz, 2013). Personas que una vez dentro de la cárcel sufren los rigores de los múltiples correlatos de exclusión de los que son parte, razón por la cual ellos e incluso sus familias ven alfamente limitado el ejercicio de sus derechos. Fenómenos que refuerzan la misma existencia de las cárceles como un gueto judicial. De hecho, de acuerdo con Mauricio Carlos Manchado (2013), el criminal bajo la lógica actual es considerado un sujeto racional y responsable de cada uno de sus actos, no un ser con todo tipo de trastornos mentales, por ejemplo, y ello en tanto esas acciones se inscriben en un mercado de beneficios y pérdidas, ya que la razón del acto criminal ya no corresponde a una desobediencia al soberano como en tiempos de antaño ni a una tendencia nata del criminal sino a una evaluación meramente económica: costo-beneficio, ganancia-pérdida respecto a un bien jurídico (Manchado, 2013).

Así visto, los individuos en general, desde el punto de vista criminal, no vendrían a ser más que residuos humanos depositados en los contenedores que ofrece el sistema penal. De ahí que el neoliberalismo es el principal limitante de la resocialización, de la educación y de la comunicación intersubjetiva de las personas privadas de la liberfad. Los medios de comunicación, por su parte, en lugar de ponerse al servicio de la resocialización, nos dice Manchado (2013), en relación a lo punitivo, optan por buscar cierta espectacularidad estereotipada al servicio del neoliberalismo, asociando criminales a ciertos tipos de piel o de condición social.

Hasta este punto, bien se puede decir, en cuanto a los fines mismos del castigo, que los autores divergen bastante hoy día, y entre ellos, podemos encontrar un primer grupo que afirma que lo punitivo cumple hoy día funciones positivas para la sociedad en general e incluso para los mismos reclusos. Funciones como la resocialización, o como la disculpa o la reparación y, desde luego, el no permitir que reine la impunidad. Por otro lado, podemos encontrar un segundo grupo de autores como el ya mencionado Wacquant (2010a) o Gabriel Ignacio 
Anitua (2010), que ponen el énfasis en una mirada crítica y en el hecho de que las cárceles hoy día cumplen una función social de poder ya sea como forma de exclusión o control étnico y social o en cuanto al hecho de que en ellas convergen múltiples correlatos de marginalidad, explosión y pobreza. Generalmente estos últimos se caracterizan por tener una postura abolicionista frente al sistema carcelario. En torno a lo que a este punto atañe, considero necesario para los fines del presente trabajo, no radicalizar la postura, y en lugar de ello tomar categorías que si bien pueden ayudar a centrar el análisis en los aspectos sociales de exclusión y pobreza, y por tanto desde su punto de vista crítico, aun así considero que herramientas como los derechos humanos permiten hablar de aspectos positivos de lo carcelario como la ya mencionada resocialización, dichas herramientas pueden verse potenciadas por la correcta implementación de las políticas públicas carcelarias.

En otras palabras, los derechos humanos, como categoría de análisis, permite analizar el ámbito penitenciario desde un punto de vista crítico y aun así facilitar aspectos positivos dentro de la misma existencia de lo penal. En cuanto a los autores que reafirman los aspectos positivos del sistema punitivo, bien podemos mencionar al escoses Antony Duff (2014), quien sostiene que:

Con respecto al castigo penal, estuve desarrollando una teoría de la comunicación de acuerdo con la cual la finalidad principal del castigo es convertirse en un proceso bidireccional de comunicación entre la comunidad y el delincuente: una comunicación de censura y de entendimiento de la ilicitud del delito, de la comunidad hacia el delincuente; $y$, a cambio, una comunicación formal de disculpa y reparación, del delincuente hacia la comunidad. También trabajé mucho sobre los principios generales de la responsabilidad penal: por ejemplo, sobre la significación (y significado) de la intención e imprudencia en el derecho penal y sobre hasta qué punto la responsabilidad debería ser construida en términos "subjetivistas" U "objetivistas" ( $p$, 92-93).

Por otra parte la autora Manuela Cunha (2014), habla de temporalidad en relación a las cárceles y a la misma identidad de las personas la cual bien podemos asociar como hemos hecho hasta al momento, a la comunicación intersubjetiva. Cunha (2014), para ser más preciso, habla de presente eterno, es decir, nos plantea que el no garantizar el derecho a la comunicación sume a los presidiarios, en medio de las rutinas y los rigores, a un presente eterno y repetitivo que atenta con el desarrollo de la personalidad y la expresión, una temporalidad que niega el pasado y las expresiones de proyecto de vida a futuro. Es decir, suprime las motivaciones de la resocialización, que si bien recordamos es el fin ético de la punitividad contemporánea. De esa forma, es necesario, como propuesta pedagógica, no solo incentivar en los reclusos el uso de los medios de comunicación y permitir el uso de las videoconferencias para establecer vínculos con los familiares, sino 
formar e instruir a las personas privadas de la libertad en el uso de tales medios y en general de las tecnologías de la información.

\section{Conclusiones}

Como vimos con Pavarini $(2009,2011)$, la misma idea de la educación y de la resocialización como paradigma punitivo, nos permite biologizar al criminal, lo cual resulta bastante pertinente y adecuado para alejarlo de aquellos correlatos de pobreza y estigmatización propios de un sistema neoliberal que los convierte en meros residuos y a las cárceles en guetos judiciales. Unos correlatos que son incluso ampliados y expandidos masivamente a través de los medios de comunicación. Por otra parte, el paradigma de la resocialización nos permite identificar además a personas con derechos, tal y como debería ser en cualquier marco jurídico y ético que se centre en lo humano.

En torno al derecho a la comunicación, entre otros tantos, hay que decir que este es interdependiente y se entrecruza con otros derechos como la expresión o el desarrollo de la personalidad, todos ellos derechos que en un marco de comunicación intersubjetiva no solo brindan los impulsos necesarios para la resocialización en forma de significaciones vitales, sino que son expresión misma de las garantías jurídicas que debería en los tiempos contemporáneos tener una persona reclusa. De forma que empoderar a personas privadas de la libertad en el uso de las tecnologías de la información y permitirles usar dichos medios para establecer contacto con sus allegados, es una forma no solo de empoderamiento sino de humanización. Un empoderamiento que puede ser posible de generarse una adecuada política pública al respecto tal y como podría concluirse del contenido de fondo de la Sentencia T-276 de 2017.

\section{BIBLIOGRAFIA:}

Anitua, G. I. (2010). Justificación del castigo e inflación penal. Universidad de Palermo, 7 de junio de 2010.

Cunha, M. (2014). The Ethnography of Prisons and Penal Confi nement. Annu. Rev. Anthropol. 2014.43:217-233.

Cuesta Quimbaya, L. A. (2015). "Política pública de resocialización. Diagnóstico de la cárcel la Picota de Bogotá. 2004 - 2013". Investigación diagnóstica con propuestas alternativas de solución Presentada como requisito para optar al título de Politóloga En la facultad de Ciencia Política y Gobierno Universidad Colegio Mayor de Nuestra Señora del Rosario. Dirigida por: María Paz Berger Arbeláez. 
Del Pozo Serrrano, F. J. (2017). La educación en las prisiones españolas: Formación y acción socioeducativa con reclusas drogodependientes. Educación XX1, 20(2), 343-363, doi: 10.5944/ educXX1.12180.

Duff, A. (2014). Entrevista a Antony Duff. Lecciones y Ensayos, Nro. 92, 2014 Entrevista a Antony Duff. ps. 301-309.

Fernandez Christlieb, F y Rizo García M. (2009). La comunicación humana como fundamento de la vida social. Editoras los miércoles sa de cr.

Foucault, M. (1975). Vigilar y castigar: nacimiento de la prisión. México: Siglo veintiuno

Lozano Ayala, A. (2008). Aspecto sobre política pública. Ejercicios e instrumentos para el análisis. Bogotá: Universidad Nacional de Colombia Lutz, B. (2013). Castigar a los pobres: el gobierno neoliberal de la inseguridad social. Espiral, Estudios sobre Estado y Sociedad Vol. XX No. 57.

Manchado, M. (2013). Neoliberalismo, prisiones y "medios" del encierro: una mirada sobre el vínculo sistema penal y los medios de comunicación en la argentina. Question - Vol. 1, N. ${ }^{\circ} 38$ (otoño 2013).

Pavarini, M. (2011). Estrategias de lucha: los derechos de las personas detenidas y el abolicionismo. Revista Crítica Penal y Poder 2011, n 1 , (pp. 307). Observatorio del Sistema Penal y los Derechos Humanos Universidad de Barcelona.

Pavarini, M. (2009). Castigar al enemigo Criminalidad, exclusión e inseguridad. Quito, Ecuador: Flacso.

Sáenz-Rodríguez, D. A. (2015). Política pública penitenciaria y carcelaria en el contexto de los procesos de reinserción social en Colombia. Revista Principia Iuris, ISSN Impreso 0124-2067 / ISSN En línea 2463-2007 Julio-Diciembre 2015, Vol. 12, No. 24 - Págs. 77 - 97.

Wacquant, L. (2010a). Castigar a los pobres: el gobierno neoliberal de la inseguridad social. Barcelona: Gedisa, 446 páginas.

Wacquant, Loïc (2010b). Las cárceles de la miseria. Segunda Edición Ampliada. Buenos Aires: Manantial.

\section{Marco jurídico:}

Declaración Universal de los derechos humanos.

Ley 65 de 1993 (Modificada por la Ley 1709 de 2014).

Sentencias: T-388 de 2014, T-378 de 2015, T-762 de 2015 y T-276 de 2017.

Resolución 7302 del 23 de noviembre de 2005.

Resolución 2392/2006. 